\title{
UM DIÁLOGO PRODUTIVO entre a Nova História Intelectual e os estudos Historiográficos
}

\author{
LUIS CLAUDiO PALERMO \\ Universidade do Estado do Rio de Janeiro \\ Rio de Janeiro | Rio de Janeiro | Brasil \\ luisclaudio72@gmail.com \\ orcid.org/0000-0001-8453-7435
}

Este artigo tem como ponto de partida o desenvolvimento da história intelectual no século XX, fornecendo especial atenção às mudanças propostas por Quentin Skinner e Reinhart Koselleck. Nesse percurso, contexto e processo histórico são chaves analíticas que emergem como primordiais para a superação das ideias como essências. Salienta-se, em seguida, a ampliação das possibilidades teóricas na história intelectual com a problematização dos contextos de recepção das ideias. $O$ argumento se desenvolve no sentido de postular que alguns dos importantes conceitos atuais - dentre os quais o de tradições eletivas - sustentam que a problematização do contexto do pesquisador pode ser vista sob a luz das noções de contexto e processo. A proposta desenvolvida no artigo lastreia-se nessas perspectivas, com vistas a postular que os referenciais teóricos e conceituais empregados pelos pesquisadores são prolíficos para uma problematização densa acerca dos estudos historiográficos. Nesse sentido, a subjetividade do pesquisador é considerada como produtiva e interconectada a uma rede de referências teóricas e conceituais. A conclusão é que o produto final - o trabalho historiográfico - não é resultado somente de chaves epistemológicas, mas também contempla o modo como o historiador se insere nos debates intelectuais de seu campo de estudo.

História intelectual - Historiografia Teoria e metodologia da bistória 


\title{
A PRODUCTIVE DIALOGUE between the New Intellectual History and the Historiographic studies
}

\author{
LUIS CLAUDiO PALERMO \\ Universidade do Estado do Rio de Janeiro \\ Rio de Janeiro | Rio de Janeiro | Brazil \\ luisclaudio72@gmail.com \\ orcid.org/0000-0001-8453-7435
}

\begin{abstract}
This article takes as its starting point the development of intellectual history in the 20th century, paying special attention to the changes proposed by Quentin Skinner and Reinhart Koselleck. In this way, context and historical process are analytical keys that emerge as primordial for overcoming ideas as essences. Then, it is emphasized the expansion of theoretical possibilities in intellectual history with the problematization of the contexts of reception of ideas. The argument develops in the sense of postulating that some of the important current concepts - among them that of elective traditions - maintain that the problematization of the researcher's context can be seen in the light of the notions of context and process. The proposal developed in the article is based on these perspectives, in order to postulate that the theoretical and conceptual references used by researchers are prolific for a dense problematization about historiographic studies. In this sense, the researcher's subjectivity is considered to be productive and interconnected to a network of theoretical and conceptual references. The conclusion is that the final product - historiographical work - is not only the result of epistemological keys, but also contemplates the way in which the historian is inserted in the intellectual debates of his field of study.
\end{abstract}




\section{INTRODUÇÃO}

A historiografia corresponde, numa acepção ampla, ao produto escrito que resulta do trabalho de pesquisadores cuja tarefa é problematizar a vida humana em sociedade e fazer dela uma "representação do passado" (Malerba 2006, 19). Nesse sentido, pode-se propor, de forma inicial e básica, que "a historiografia é uma forma de cultura escrita cujo objetivo primaz e primário é apresentar os resultados de uma pesquisa histórica" (Palermo 2017b, 300).

Para além da definição sumária e básica de historiografia como resultado escrito de uma pesquisa histórica, é pertinente adicionar que o sentido do conceito historiografia contempla também os estudos que se preocupam em problematizar a trajetória da escrita da história, ao longo do tempo. Neste último sentido estão inseridos elementos que nos permitem pensar numa espécie de cultura historiográfica ou, de forma mais clara, a escrita da história como resultado de "práticas culturais necessárias de orientação social" (Malerba 2002, 21).

Essa cultura historiográfica favorece a discussão a respeito da historicidade do conhecimento histórico. Contempla, nesse sentido, tanto a crítica às interpretações sobre o passado (mais voltada à história das ideias) quanto a possibilidade da crítica concernente aos fundamentos epistemológicos presentes na construção da perspectiva das autoras e autores (mais próximo à história dos conceitos e à teoria da história).

As pesquisas que envolvem a produção de conhecimento sobre a historiografia remontam ao século XIX. Contudo, o crescimento mais forte e a difusão mais ampla dos trabalhos vinculados à historiografia ocorreram após a década de 1980. Tais crescimento e difusão foram motivados, dentre outros fatores, pelas importantes mudanças experimentadas pela produção do conhecimento histórico, especialmente desde a segunda metade do século XX (Rodrigues 2009, 181-182; Cf. Burke 1997). Esse processo de transformações estimulou os pesquisadores a mirarem sua própria produção historiográfica. Por esse caminho, passaram a se preocupar, de forma mais contundente, com a historicidade das pesquisas históricas (Escosteguy Filho 2015, 104).

O historiador Pedro Caldas, baseado numa ideia do filósofo Arthur Danto, expõe um argumento que ilustra bem a importância dos estudos historiográficos. Segundo esse historiador, Danto afirma que a filosofia deve pensar a si própria, ao refletir sobre um objeto que faz parte do mundo (Caldas 2012, 233). Ora, desse modo, pode-se concluir que de nada vale (ou pouco vale) pensarmos problemas históricos, se não refletirmos acerca da própria historicidade dessa produção do conhecimento histórico (Caldas 2012, 233).

Cabe aduzir que a produção do conhecimento histórico envolve, ao menos, o uso de fontes, a aplicação de uma metodologia e o emprego de referências teóricas. Além disso, ainda que o pesquisador demonstre suas preocupações com a isenção, neutralidade e imparcialidade, sabe-se que sua produção está, em alguma medida, envolta e composta de valores ideológicos e políticos (Cf. Mauad; Cavalcante 2013).

Trata-se, pois, de uma produção que não se desvincula das questões atinentes ao mundo do pesquisador e de sua visão acerca da sociedade, do que é justo, do que é belo etc. (Cf. Catroga 2001, 49). Com isso, é pertinente expor que, entre o observador e o objeto, interpõem-se um conjunto de elementos que enformam e informam o processo de pesquisa; logo, tal conjunto mostra, em alguma medida, sua interveniência no produto final. 
Em razão do que foi delineado, é conveniente realçar que muitas discussões conceituais e propostas teórico-metodológicas têm sido colocadas como produtivas para os estudos historiográficos, especialmente desde às duas últimas décadas do século XX. É nessa trilha que este trabalho ora iniciado se constitui. Seu cerne temático corresponde à relação entre história intelectual e a historiografia. Seu objetivo é analisar como o desenvolvimento daquela pode ser produtivo para esta.

Metodologicamente, o trabalho se constitui de análises e interpretações de alguns autores importantes para o campo da história intelectual. O intento é extrair da obra desses autores fulcros teórico-metodológicos e conceituais que possam contribuir para propostas que sejam prolíficas para os estudos atinentes à historiografia.

O artigo está seccionado em três partes, além da Introdução e Considerações finais. $\mathrm{Na}$ primeira, explora-se o desenvolvimento de ferramentas concernentes à história intelectual, para, em seguida, na segunda parte, extrair e analisar um dos esteios da nova história intelectual. $\mathrm{Na}$ terceira e derradeira, são discutidos como essas ferramentas podem ser tomadas de empréstimo para uma problematização produtiva de pesquisas que se concentram em estudos historiográficos. Intenta-se, ao final, contribuir, em alguma medida, com os debates e referências epistemológicas que sirvam aos pesquisadores que estejam interessados em pesquisas historiográficas.

\section{CONSIDERAÇÕES GERAIS SOBRE O DESENVOLVIMENTO DA HISTÓRIA INTELECTUAL ATÉ OS ANOS 1970}

O historiador argentino Elías José Palti argumenta que Arthur Lovejoy é uma figura primordial no campo da história das ideias, tendo em vista que ele contribuiu para que se fundasse, na primeira metade do século XX, uma Escola voltada para o desenvolvimento de estudos concernentes à história das ideias, com sede na Johns Hopkins University (Palti 2007, 298). A obra de Lovejoy e os trabalhos dessa Escola colaboraram, sobremaneira, para o desenvolvimento desse campo de estudo sobre as ideias, notadamente no período entre os anos de 1940 e 1950 (Palti 2007).

Palti chama a atenção para dois pontos caros aos postulados de Lovejoy: primeiro, as ideias transcendem seus contextos. Nessa linha, as ideias circulam e, consequentemente, podem assumir sentidos diferentes; segundo, as ideias contribuem para que os historiadores tenham uma compreensão geral da história porque elas produzem efeitos em nossa "conduta y nuestro modo de experimentar aquellas afecciones que le dieron origen" (Palti 2007, 298).

Por esse caminho, as ideias ganham concretude contextual e, em decorrência, uma justificativa teórica para que possam figurar como objeto de estudo histórico. Podem ser vistas, então, "como proposição ontológica que afirma a existência "real" das idéias na história (no sentido de matéria do conhecimento histórico)" (Falcon 1997, 92, com grifos no original).

Em torno dos anos 1960, a história das ideias, conforme erigida por Lovejoy, sofreu críticas contundentes e demonstrou sintomas de esgotamento. No segundo pós-guerra, “[...] De um modo geral, o que se costumava apontar como deficiente era o excessivo idealismo ou essencialismo" (Ambrosini 2010, 3) que estava presente na forma de análise dos pesquisadores cujo objeto de estudo eram as ideias. É como se a história das ideias remetesse "a textos nos quais os conceitos articulados" constituíssem "os agentes históricos primários, 
vindo a seguir as pessoas dos portadores desses conceitos, enquanto as chamadas relações externas são entendidas como simples condições de existência das idéias propriamente ditas" (Falcon 1997, 93).

Convém trazer outra crítica feita à história das ideias da linha de Lovejoy. Palti seleciona, por exemplo, o apontamento restritivo que Lewis Namier fez a Lovejoy, em 1955, através do artigo "Human Nature in Politics". O historiador argentino assinalou que a principal crítica de Namier enfocava a não coerência histórica dos seres humanos, sobretudo no que se refere às suas ideias, uma vez que,

\section{[...] los hombres no han tenido nunca mayores problemas en contradecir sus ideas siempre que lo consideraron necesario. Tomar las mismas como base para comprender el sentido de sus acciones resultaría, por lo tanto, sencillamente ingenuo. En definitiva, lo que Namier ponía en cuestión era la legitimidad misma de la historia intelectual, el objeto de su empresa (Palti 2007, 299).}

Esse foi, portanto, um período em que a história das ideias sofreu contestações. Em função disso, seus defensores passaram a ter que lidar com sua legitimação como campo de estudo, haja vista que a história social predominava na produção de conhecimento histórico ocidental. ${ }^{1}$ Em razão do exposto, é importante acrescentar que, a partir "[...] des annés 1960, cette histoire des idées a été violemment mise em question par l'histoire sociale qui conteste à la fois ses méthodes et ses objets" (Noiriel 1996, 131).

Nessa fase de crise de legitimidade, Palti (2007) aponta os trabalhos da Escola de Cambridge (notadamente Quentin Skinner) e da Begrisffsgeschichte (sobretudo a história dos conceitos de Reinhart Koselleck) como fundamentais para a renovação ocorrida na história das ideias, a partir dos anos 1960. Essas novas propostas (e outras não abordadas aqui) influenciariam, em alguma medida, a renovação no campo da história das ideias.

Sobre o trabalho do historiador dos conceitos alemão Reinhart Koselleck, cumpre enfatizar a distinção que ele faz entre a história dos conceitos e a história social, a fim de registrar, contundentemente, as diferenças entre elas e, por conseguinte, marcar o valor e o lugar da história dos conceitos para a história social (Cf. Koselleck 2006, 97-118). Esse autor assinala que a força metodológica da história dos conceitos advém da possibilidade de se tratar conjuntamente espaço e tempo distintos numa perspectiva sincrônica de análise.

Ao empregarmos essa chave teórico-metodológica, ganhamos a possibilidade de pensar os conceitos no que eles apresentam de continuidade, ou seja, a possibilidade de estudá-los compondo uma homologia entre as situações distintas, definindo uma espécie de quadro conceitual. Cumpre chamar a atenção para o fato de que, ao mesmo tempo que compomos uma visão sincrônica dos conceitos, podemos observar suas especificidades, ou seja, devemos estar atentos, também, à sua perspectiva diacrônica.

1 Vale chamar a atenção para o que Falcon chama de dois grandes adversários da história das ideias. "Como disciplina histórica, a história das idéias, apesar de sua imponente longevidade e prestígio [o autor remete, aqui, aos estudos filosóficos que sempre tiveram as ideias como objeto], teve contra si dois grandes adversários: a tradição marxista e a historiografia francesa dos Annales" (Cf. Falcon 1997, 92, grifo no original). 
Um exemplo que ilustra os aspectos teórico-metodológicos expostos acima encontra-se numa explicação em que Koselleck diferencia palavra de conceito. Esse historiador aponta como pontos importantes na operacionalização dos conceitos a possibilidade de generalização e polissemia. O excerto a seguir ajuda a esclarecer o argumento:

\begin{abstract}
Os conceitos são, portanto, vocábulos nos quais se concentra uma multiplicidade de significados [diacronia]. O significado e o significante de uma palavra podem ser pensados separadamente. No conceito, significado e significante coincidem na mesma medida em que a multiplicidade da realidade e da experiência histórica se agrega à capacidade de plurissignificação de uma palavra, de forma que seu significado só possa ser conservado e compreendido por meio dessa mesma palavra. Uma palavra contém possibilidades de significado, um conceito reúne em si diferentes totalidades de sentido [possibilidade sincrônica] (Koselleck 2006, 109, grifos do autor).
\end{abstract}

Enquanto uma palavra pode ter seu sentido definido pelo uso, os conceitos necessitam, por outro lado, da "totalidade das circunstâncias políticosociais e empíricas", que lhes conferem um sentido de totalidade ou um corpo edificado (Koselleck 2006, 109). "[...] De allí deriva la característica fundamental que distingue a un concepto: lo que lo define es, precisamente, su capacidad de trascender su contexto originario y proyectarse en el tempo" (Palti 2007, 300), sendo usado em distintas situações, a partir de um corpo de matriz referencial a ser aplicado em diversas situações históricas. Desse modo, as palavras são usadas em situações de vida e os conceitos aplicados para compreender situações históricas.

O que convém reter dessa contribuição complexa e prolífica de Koselleck (2006) é que a história dos conceitos favorece a construção de possibilidades que permitem conferir outra dimensão para as ideias. Em vez de apenas se ater à historicidade das ideias num determinado contexto, o teórico alemão nos convida, com efeito, a compreender que os conceitos "contêm possibilidades estruturais" (Koselleck 2006, 116). Desse modo, não só a diacronia, mas também - e especialmente - a sincronia pode (e deve) ser acionada na elaboração dos conceitos.

Pode-se afirmar, a partir de Koselleck, que os conceitos "trascienden las esferas de sociabilidad inmediata, [e] sirven de índice de las variaciones estructural" (Palti 2007, 301). Há, implicitamente nessas propostas do historiador alemão supracitado, uma ruptura com o postulado das ideias como essências, que foi a crítica mais cara feita a Lovejoy, pois, para o intelectual alemão, conceitos devem ser apreciados historicamente.

No que concerne ao trabalho da Escola de Cambridge, Palti argumenta - referindo-se muito especialmente, à tese de Quentin Skinner, sobretudo levando em consideração o texto "Meaning and Understanding in the History of Ideas" - que o historiador britânico se contrapôs a Lewis Namier ao defender que as ideias podem (e devem) ser pesquisadas a partir de seu contexto, contemplando a intencionalidade do autor. Para tanto, Skinner superou o pressuposto de que as ideias têm conteúdo essenciais e universais. Desse modo, o teórico em questão '[...] censurava o procedimento-padrão do 'textualismo', que consistia, em suas expressões mais caricaturais, em 'ler e reler' determinado texto até chegar-se a uma compreensão correta de seu significado" (Silva 2009, 307 , grifos do autor). 
O historiador inglês propôs, então, que as ideias devem ser compreendidas em seu uso público, levando-se em consideração seu contexto específico e salientando o diálogo (e rivalidade) que as ideias têm com outras que estão presentes em seu tempo. Em razão disso, o pesquisador deve superar a instância meramente textual das ideias e "[...] aceder a la trama de relaciones e intencionalidades por los que dichos textos se constituyen como tales actos de habla" (Palti 2012, 31).

A partir das colocações de Palti (2012), percebe-se que Skinner visa conectar, dessa forma, intenção autoral, contexto e interlocutores. Com isso, Skinner sustenta que há a possibilidade produtiva de se pensar as ideias dentro de um quadro contextual de disputas intelectuais intersubjetivas que nos permitem alcançar, não de forma ingênua, os sentidos das ações/ideias dos autores.

Ressalta-se, nesse caminho, a contribuição da Escola de Cambridge, notadamente Skinner - no que se refere à importância de se levar em consideração o contexto em que se inserem as ideias. A partir desse postulado, as ideias não mais são consideradas como perenes (Cf. Chaubet 2009, 181), mas devem ser situadas precisamente no plano dos usos públicos da linguagem (Cf. Palti 2007, 299). Pode-se argumentar, nesse sentido, que "[...] a abordagem skinneriana da História Intelectual dirige seu foco para o significado (sic) dos textos históricos como manifestações de atos linguísticos intencionais efetuados em determinados contextos de convenções linguísticas e normativas" (Silva 2009, 307).

Segundo Palti (2007, 299), a Escola de Cambridge trouxe à baila, para o campo da história das ideias, um primeiro antecedente do chamado giro linguístico. $\mathrm{O}$ argumento desse historiador lastreia-se na premissa de que integrantes dessa Escola, especialmente Quentin Skinner e John Pocock, conseguiram problematizar o contexto de emergência (Palti 2012, 25) dos sujeitos históricos pesquisados por eles. Assim, de acordo com Palti (2012), esses pesquisadores supracitados foram capazes de problematizar o uso das ideias em (inter)relação ao contexto em que os atores (protagonistas das ideias pesquisadas) se inseriam.

Nessa trilha, é valoroso acrescentar que, para Francisco Falcon, a história intelectual se difere da história das ideias, na medida em que

\begin{abstract}
[...] A história intelectual remete a textos bem mais abrangentes, uma vez que ela inclui as crenças não-articuladas, opiniões amorfas, suposições não-ditas, além, é claro, das idéias formalizadas. Além do mais, a história intelectual preocupa-se com a articulação desses temas às suas condições externas [...]. Uma consequência interessante é assim a tendência da história intelectual romper os limites disciplinares estabelecidos já que visa a inserir o estudo das idéias e atitudes no conjunto das práticas sociais (Falcon 1997, 93).
\end{abstract}

Em função do que foi delineado, o trabalho desenvolvido por tais pesquisadores foi capaz de colocar em evidência as ideias numa teia de relações contextuais, o que lhes permitiu analisar, pragmaticamente, as vinculações entre a enunciação das ideias e seu contexto (seus interlocutores no período). Nesse sentido, "[...] la trama das relaciones linguísticas" (Palti 2012, 29) se torna um fator nuclear para compreender a produção das ideias. Seguindo essa linha de raciocínio, o pesquisador estaria habilitado a "[...] descobrir, tras tales actos de habla, la intencionalidade (consciente o no) del agente (su fuerza ilocutiva), es 
decir, qué hacía éste al afirmar lo que afirmo em el contexto em que lo hizo" (Palti 2012, 29, grifo do autor).

Ao refletir acerca dessa mudança engendrada no núcleo da história das ideias, Palti argumenta que foi estabelecida, desde então, condições de possibilidade de o pesquisador explorar as ideias não como mera enunciação, mas também levar em conta sua relação com os interlocutores e com o meio social que envolve o sujeito histórico. Abriu-se, conseguintemente, um caminho de análise das ideias como discursos, logo, como atos de fala inscritos temporal, geográfica e socialmente (num contexto). Nessa linha de raciocínio, vale registrar que, "[...] a metodologia contextualista de Skinner concentra-se no estudo da dimensão pragmática do discurso político" (Silva 2009, 302). ${ }^{2}$

\section{UMA DAS NOVAS PROPOSTAS FORMULADAS A PARTIR DOS ANOS 1970: O CONTEXTO DE RECEPÇÃO EM SUAS TRÊS DIMENSÕES}

Como desdobramento desses debates e do desenvolvimento da história das ideias, Palti indica uma outra ordem de mudança ocorrida na teoria do conhecimento. Ela teve grande influência na produção do vasto campo das humanidades, sobretudo após os anos 1970. Trata-se da problematização do “contexto de recepción" (Palti 2012, 35). Tal mudança está no bojo de um conjunto de "[...] turns surgidos na semiótica, na psicanálise, na filosofia, na antropologia e na história" (Avelar; Gonçalves 2015, 58, grifo dos autores).

Um dos principais turns (viradas ou giros) que contribuíram para influenciar a problematização do contexto de recepção é o giro linguístico. Deve-se, com efeito, reconhecer que não existe um único giro linguístico (Cf. Avelar; Gonçalves 2015). Trata-se, pois, de um termo polissêmico e que pode assumir múltiplas possibilidades (Cf. Avelar; Gonçalves 2015). Segundo Noiriel, “[...] Le 'programme' de recherche annoncé lors du coloque de Cornell em 1980 n'a jamais véritablement été mis en pratique collectivement" (Noiriel 1996, 143).

Não obstante o caráter polissêmico do giro linguístico e de não haver um programa de pesquisa comum claramente identificável, é imperativo selecionar e centralizar, para efeito da discussão que aqui se estabelece, o papel da linguagem como questão epistêmica e ontológica importantes (Avelar; Gonçalves 2015, 60). Diante do que foi exposto, o núcleo do problema que envolve o contexto de recepção, segundo Palti (2012), encontra-se no caráter mediador que a linguagem impõe ao pesquisador que investiga a vida humana em sociedade.

2 Vale registrar que Skinner, por exemplo, foi criticado por adotar uma perspectiva excessivamente contextualista. Para uma aproximação mais aprofundada desse debate e de algumas respostas dadas pelo pesquisador britânico, sugere-se a leitura do artigo de Ricardo Silva (2009).

${ }^{3}$ Inicialmente, cumpre apontar que Palti (2012) analisa duas dimensões concernentes ao contexto de recepção: a primeira se refere ao contexto de emergência dos atores sociais (quando historicamente os fatos emergem); a segunda está ligada ao contexto do pesquisador que recebe os dados/acontecimentos que surgiram no contexto de emergência. Portanto, a primeira tem relação com os acontecimentos e a segunda com a produção de um conhecimento acerca dos acontecimentos. A terceira dimensão corresponde a um novo patamar analítico, pois remete ao contexto de produção intelectual do pesquisador. Portanto, tem relação com o contexto epistêmico-institucional do pesquisador (Palti 2012, 49), ou seja, com as disputas intelectuais que envolvem seu universo de produção do conhecimento. 
Há, desse modo, um questionamento epistemológico de que nosso conhecimento do mundo não ocorreria de forma direta e objetiva. Por essa linha de raciocínio, o conhecimento é tratado como um processo mediado pela linguagem. E tal mediação, cabe registrar, colocaria dificuldades de acesso ao conhecimento pleno de uma realidade. "Por isso, [nesta perspectiva, a experiência nunca pode ser apartada da linguagem que estrutura suas articulações" (Avelar; Gonçalves 2015, 65).

Ao problematizar o contexto de recepção, Palti (2012) coloca em discussão, sinopticamente, a "[...] natureza profundamente histórica e condicionada" (Avelar; Gonçalves 2015, 67) do relato feito pelo historiador (pesquisador). Em outros termos, “[...] Ya no es el 'contexto de Maquiavelo' [do pensador estudado], sino el próprio 'contexto de Skinner' [do próprio pesquisador que pesquisa o pensador estudado] el que se convertiría em objeto de estúdio" (Palti 2012, 35, grifos do autor).

As viradas (ou turns) operadas no âmbito do giro linguístico trouxeram para reflexão histórica, a partir dos anos 1970, não somente o “[...] questionamento significativo de toda e qualquer relação privilegiada entre linguagem e realidade" (Rangel; Araújo 2015, 321), mas, como corolário, uma possibilidade de problematizar, de forma mais evidente, o discurso do pesquisador. Tal movimento trouxe à tona o modo de construção do conhecimento do pesquisador, além das possibilidades interpretativas empregadas por ele. Conseguintemente, estabeleceu-se, no seio das ciências humanas, uma crise "de la hermenéutica tradicional" (Palti 2012, 64).

Portanto, os dilemas enfrentados nas pesquisas realizadas no campo das ciências humanas centraram-se, grosso modo, entre a ênfase na problematização do contexto de emergência das ideias (contexto histórico estudado) e o realce no contexto de recepção dessas ideias por parte dos pesquisadores (contexto histórico da produção do conhecimento histórico). Em outros termos, as premissas teóricas inscritas nas pesquisas deveriam deterse mais na compreensão dos sentidos emanados pelas sociedades humanas ou deveriam levar em conta, com maior destaque, a perspectiva do discurso produzido pelo pesquisador? Estava em jogo, pois, uma antinomia entre o objetivismo e relativismo (Cf. Cardoso 1997; Cf. Palti 2012).

Como desdobramento, cumpre registrar que a crise hermenêutica desencadeou um movimento teórico que incentivou a teoria a mirar também sobre si mesma. Isso produziu o que Palti chama de "el contexto metacrítico" (Palti 2012, 51), que corresponde à terceira dimensão contextual mencionada por esse autor em voga. Tal mudança ocorreu porque as problematizações colocadas pelas viradas (turns), conforme acima apontado, atravessaram "un nuevo umbral" (Palti 2012, 48), em nível teórico, propiciando à história intelectual um desenvolvimento significativo no período após os anos 1970. Com isso, a história intelectual experimentou, logo em seguida, seu período de

\footnotetext{
${ }^{4}$ Externo, desde já, que esses argumentos epistemológicos são pertinentes e de grande impacto. Tanto que "[...] As reflexões dos partidários do giro linguístico trouxeram, a nosso ver, incontornáveis ganhos para o historiador" (Avelar; Gonçalves 2015, 67). Não obstante, minha posição é que não tornam o conhecimento das pesquisas apenas realidades produzidas pela linguagem. Sinteticamente, considero que a experiência, apesar do grau de mediação da linguagem, não é totalmente inacessível. Nesse sentido, a análise do historiador (ou seu discurso, seja como for) não está plenamente desprovida de um conteúdo de experiência que dá base para as interpretações. A experiência, portanto, não se resume nem se reduz ao significado linguístico que lhe dá sentido, apesar de ser influenciada, em alguma medida, por tal significado.
} 
maior sucesso “[...] à la fin des années 1980 et au long des années 1990" (Chaubet 2009, 179).

Os debates adentraram um novo terreno analítico e reflexivo. De forma mais marcante, passou a ser possível, no período que envolvia a produção do conhecimento histórico nos anos 1970 e 80, colocar em discussão os referenciais teóricos e conceituais que envolvem e referenciam a produção do discurso do pesquisador. Portanto, a produção intelectual conseguiu situar um contexto crítico sobre si mesma ou sobre seu próprio contexto de recepção (Cf. Palti 2012, 49).

Cumpre reiterar que a crítica, nesse cenário, “[...] se vuelve entonces doblemente reflexiva y se convierte em uma metacrítica" (Palti 2012, 48). Foram criadas, então, as condições para se problematizar não os discursos críticos, mas "como éstos pueden formarse, intercambiarse y circular socialmente" (Palti 2012, 49). Assim, colocou-se em evidência os discursos críticos (teóricos e conceituais) em relação a seu contexto epistêmicoinstitucional (Cf. Palti 2012, 49).

É conveniente assinalar que Palti (2012) conduz sua argumentação final no sentido de defender não uma perspectiva relativista soberana. A análise do autor a respeito da influência do giro linguístico na história intelectual teve um sentido nuclear e matricial de mostrar que devemos superar as formas tradicionais e ingênuas do objetivismo. Sinopticamente, a análise do historiador argentino intenta explicar como as mudanças trazidas pelo giro linguístico conseguiram potencializar, em termos teóricos, a história intelectual, gerando ganhos, mas sem levá-la ao relativismo total.

\section{HISTÓRIA INTELECTUAL: ALGUNS APORTES QUE CONTRIBUEM PARA OS ESTUDOS HISTORIOGRÁFICOS}

Diante do que foi exposto na seção anterior, pode-se depreender, a partir da linha de raciocínio de Palti (2012), que os estudos desenvolvidos sobre a historiografia tem conexões evidentes com a história intelectual, uma vez que se tornou possível aos historiadores, de forma crescente, problematizar o contexto de recepção e o contexto metacrítico de sua própria produção. Portanto, a partir dessas discussões, pode-se problematizar, no núcleo da análise contido nos trabalhos historiográficos, questões que remetem à história intelectual, produzindo um diálogo com a história da historiografia. Nesse sentido,

[...] el historiador sea mucho más consciente de que el cambio no es algo exterior y "objetivo" que afecta únicamente a los agentes del pasado. También el historiador, el filósofo o el politólogo están localizados en un contexto y forman parte de un mundo en devenir, como la historia de la historiografía y de las ciencias sociales no han dejado de señalar. Abora bien, puesto que tanto los objetos observados como el observador son sujetos móviles, la omnipresencia del cambio bistórico nos obliga a asumir la inevitable provisionalidad y caducidad de nuestros esquemas interpretativos (Fernández Sebastián 2014, 8, aspas do autor e grifos em itálicos meus).

${ }^{5}$ Estou situando, neste ponto, uma outra (terceira) dimensão apontadas aqui, a partir de Palti (2012). Se a primeira se referia ao contexto de emergência e a segunda ao de recepção, agora o historiador argentino chama a atenção para a possibilidade de problematização dos discursos críticos dos pesquisadores. Neste caso, o prefixo meta indica a função de transcendência e reflexão sobre si. 
Em decorrência, as pesquisas que enfocam na historiografia têm ganhado ferramentas conceituais e teóricas que permitem aos pesquisadores enxergá-la não somente sob a dimensão da história social ou cultural, mas também sob a rubrica da história intelectual, tendo em vista que se pode problematizar, no núcleo da análise contida nos trabalhos historiográficos, um "processo de ordem intelectual" (Nicolazzi 2014, 29).

É importante evidenciar que, sobretudo no período após os anos 1970, os trabalhos historiográficos ganharam, de maneira mais robusta, a possibilidade de ser problematizados em suas vertentes intelectual e epistemológica. Nesse sentido, cumpre iluminar a afirmação de Chaubet (2009, 190) de que a história tradicional das ideias passou " $d$ 'une histoire des significations [das ideias] à une histoire des intelectuels".

Diante disso, é preciso ressaltar que duas referências são substanciais para a análise que vem sendo desenvolvida aqui. Elas aparecem contundentemente na argumentação de Palti (2007) e Fernández Sebastián (2014) sobre a nova história intelectual. Tratam-se, conforme delineado precedentemente, da Escola de Cambridge e da história dos conceitos capitaneada por Koselleck. ${ }^{6}$ Essas referências são evocadas, de forma reiterada, porque contribuíram substancialmente para dar lastro teórico-metodológico ao campo da história intelectual.

Cumpre notar que, especialmente a partir dos anos 1960/70, a referência contextual derivada da influência da Escola de Cambridge tornou-se, no âmbito da história intelectual, um dos pontos fortes destacados por muitos autores (Cf. Palti 2007; Chaubet 2009; Silva 2009). Nessa linha contributiva, de acordo com Ambrosini (2010, 3), o texto do passado só poderia ser compreendido, caso se inscrevesse num contexto histórico e linguístico. Logo, o caráter descritivo e, sobretudo, pragmático do texto se sobreporia, nesta perspectiva, a "qualquer inclinação normativa" (Ambrosini 2010, 3).

Em adendo à perspectiva contextualista, torna-se preponderante registrar que a matriz de análise edificada pela história dos conceitos, conforme a capitaneada por Koselleck, trouxe à tona o caráter primordial de uma análise dos conceitos com base na concatenação entre os níveis temporais (Cf. Tomich 2011). Segundo Marcelo Gantus Jasmin,

[...] a perspectiva de mudança conceitual adquire traços diacrônicos de dinamismo histórico e acentos claramente hermenêuticos que estão ausentes, ou são muito tênues, nas proposições fundadoras do contextualismo linguístico de Cambridge. Para a história conceitual koselleckiana, continuidades e mudanças conceituais tornam-se temas centrais (Jasmin 2005, 32-33).

\footnotetext{
${ }^{6}$ Francois Chaubet (2009) chama a atenção para a importância dos trabalhos de Michel Foucault, da sociologia histórica bourdiesiana, entre outros, para o campo da história intelectual. Vainfas $(1997,136)$, por exemplo, mostra-nos que “[...] ao publicar sua L'archeologie du savoir (Arqueologia do saber), em 1969, [Foucault] pôs em xeque os paradigmas ocidentais do conhecimento científico, o racionalismo e o próprio saber histórico". Mas, este artigo não visa o escrutínio do campo da história das ideias nem da história intelectual, mas apenas trazer à tona teorias, conceitos e teses que dialogam com o propósito aqui delineado.
} 
Essa visão "[...] incorporou, então, um elemento teórico-metodológico caro à compreensão a respeito da vida humana: a noção de tempo estrutural" (Palermo 2017b, 311). Nesse sentido:

[...] a história passou a ser vista como um campo de conhecimento capaz de articular os acontecimentos singulares e inéditos com a estrutura que dá um tom de integralidade, de continuidade a esses acontecimentos. A história passou a articular, pois, a curta duração com a longa duração; passou a articular uma perspectiva sincrônica com a diacrônica. Nessa fase, os historiadores puderam passar a considerar a história a partir de uma cadeia causal ampla e não trivial (Palermo 2017b, 312).

Em vista dessas considerações, é pertinente ressaltar que o conceito de "tradiciones electivas", de Javier Fernández Sebastián (2014), permite concatenar essas duas importantes propostas teórico-metodológicas assinaladas anteriormente: contexto e processo histórico. Ademais, mostra-se uma referência profícua para análises que remetem à história da historiografia (e aos estudos historiográficos de forma geral), primordialmente no que se refere à problematização do contexto de recepção do historiador (seu contexto de escrita amplo) e a seu contexto metacrítico (as discussões intelectuais que se forjam em termos teóricos).

"Tradições eletivas" ou "tradições seletivas" (Cf. Fernández Sebastián 2014) é um conceito cunhado e construído originariamente com visas a contribuir para os estudos ligados à história das ideologias, bem como dos movimentos políticos e sociais, principalmente aos que se inscrevem nos séculos XVIII, XIX e XX. A formulação do conceito é decorrente das discussões enfrentadas pelo historiador em mencionado sobre a antinomia entre tradição e modernidade.

O ponto de partida nuclear do argumento é que, especialmente na passagem da história moderna à contemporânea, os movimentos sociais e políticos emergentes procuraram enfatizar as mudanças inscritas precisamente no interior de suas propostas, a fim de tentarem marcar uma descontinuidade plena e cabal em relação à tradição.

A ideologia inerente a esses movimentos (o liberalismo é um dos que esse pesquisador mais destaca) tratou de salientar, pujantemente, o contraste entre as sociedades modernas e as tradicionais, dando um cariz de total ruptura a tal contraste. Encontra-se, subjacente à essa proposta, uma noção de tempo que não oferece a possibilidade para se enxergar as continuidades, visto que o realce, nessa perspectiva, recai eminentemente sobre a ideia de ruptura temporal, o que coloca a tradição com uma representação negativa, problemática, ou seja, como algo a ser superado.

O historiador em apreço defende, por outro lado, que esse modelo argumentativo e teórico desconsidera as permanências que são deixadas pela tradição e que sobrevivem ao processo de inovação, mudança, ruptura ou a seus discursos. Tendo por base a noção de tempo como um processo, de acordo com o que foi formulado por Reinhart Koselleck (2006), o professor da Universidad del País Vasco contrapõe-se a essa antinomia plena (modernidade/tradição) e sustenta que a história intelectual e do pensamento político seja sensível à compreensão temporal mais refinada e que esteja aberta a compreender que "[...] que la invención misma [a inovação] bebe muy a menudo en las fuentes de la tradición” (Fernández Sebastián 2014, 20). 
Para fundamentar sua posição nessa contenda, um dos argumentos mais caros a esse autor é que a tradição não é uma herança meramente recebida do passado, mas sobretudo uma interpretação do passado que é realizada efetivamente no presente (Fernández Sebastián 2014, 18). Por isso, o que é deixado pelo passado como herança é algo complexo, multiforme, poliédrico. Logo, os herdeiros do passado têm a capacidade e o poder de selecionar os acontecimentos e produzir angulações que estejam em consonância com suas ideologias, preferências, perspectivas etc. Vale acrescentar que essa operação não é realizada sem que sejam colocadas em jogo suas (a dos que vivem no presente) expectativas de futuro. Desde então, portanto, "o futuro não é [era] mais como era antigamente".

Seguindo essa linha de raciocínio, depreende-se que a tradição não deve somente ser enxergada como um passado que sobreviveu, mas, eminentemente, "como um legado histórico imaginado y elaborado por el próprio legatário" (Fernández Sebastián 2014, 18). Cabe frisar que, ao propor esse deslocamento analítico, o autor abre, outrossim, uma perspectiva sensível aos embates intersubjetivos.

A partir dessa análise, descortina-se uma relação entre passado, presente e futuro que coloca outra hierarquia de importância entre esses extratos do tempo (Cf. Koselleck 2001), uma vez que, na perspectiva de Fernández Sebastián (2014), o presente interpreta o passado e o elabora com base numa possibilidade de ação política em seu tempo (presente), com vistas ao futuro. Muda-se, dessa forma, o vetor de compreensão da tradição. Esta deixa de ser formada por uma linha de comunicação do passado ao presente. Por esse raciocínio, o presente e o futuro ganham entonação primordiais na elaboração/construção da tradição, mas não como invenção em si. ${ }^{8}$

Tradições eletivas têm, portanto, conexões com a seleção de acontecimentos e ideias feitas pelo presente e no presente, contemplando também expectativas de futuro. Desse modo, “[...] Podemos entender pues las tradiciones electivas de los modernos [...], más que como uma herencia recibida de las generaciones anteriores, como un legado histórico imaginado y elaborado por el propio legatário" (Fernández Sebastián 2014, 18). Desse modo,

[...] Podemos entender pues las tradiciones electivas de los modernos (a las que podría convenir el lema ex innovatio traditio), más que como uma herencia recibida de las generaciones anteriores, como un legado histórico imaginado y elaborado por el propio legatario. De entre todos los passados posibles, cada actor colectivo selecciona de acuerdo con sus preferencias aquellos hechos, autores o episodios históricos en los que de algún modo se reconoce: aquellos que mejor se adaptan a sus necesidades de legitimación y a sus expectativas de futuro (Fernández Sebastián 2014, 18).

\footnotetext{
7 Música "Índios". Compositor: Renato Russo. A canção foi gravada pelo grupo Legião Urbana, no Álbum intitulado "Dois", lançado em 1986 pela gravadora EMI. Fonte: http://www.legiaourbana.com.br/dois.html. Acesso em: 14 ago. 2017.

8 Essa colocação tem o sentido de expressar que Fernández Sebastián visa, em seu texto, distanciar-se do conceito de invenção da tradição de Eric Hobsbawm e Terence Ranger (2006). No entanto, cabe registrar, por outro lado, que Franzini $(2014,36)$, ao comentar o texto de Fernández Sebastián, pondera que não considera que a "distinção entre tradição eletiva [de Fernández Sebastián] e tradição inventada [de Hobsbawm e Ranger]" seja tão substancial assim, conforme busca fazer Fernándes Sebastian (2014). Minha posição/interpretação se alinha à de Franzini (2014).
} 
O que pretendo reter e evidenciar, com base em Fernández Sebastián (2014), são as contribuições que esses debates teóricos no campo da história intelectual podem oferecer para estudos que remetem à historiografia. Tais contribuições apontam para três dimensões que estão envolvidas no processo de construção do conhecimento. Essas dimensões podem ser problematizadas isoladamente ou podem se combinar. São elas: (i) o valor e força do contexto de recepção dos autores; (ii) a proficuidade do contexto metacrítico; (iii) a importância da inserção da subjetividade num campo intelectual, evidenciando o vigor presente nas contendas e diálogos intersubjetivos como algo crucial na construção do conhecimento por parte de um pesquisador. ${ }^{\text {" }}$

Sobre a primeira dimensão, ou seja, o "contexto de recepción" dos autores (Palti 2012, 35), é preciso admitir que essa referência conceitual de Fernández Sebastián pode ser aplicada aos estudos que remetem à historiografia, uma vez que tal referência nos ajuda a analisá-la sob o ponto de vista de sua ligação contextual com o mundo em que são produzidas as obras historiográficas. E, nesse sentido, cabem destaques a alguns tipos de fatores que impactam na escrita da história: sociais, políticos, identitários, filosóficos, jurídicos, culturais, econômicos, intelectuais, entre outros possíveis.

A investigação no âmbito da historiografia demanda que se perscrute as vinculações que as pesquisas têm com o tempo presente ou, conforme Mastrogregori (2006, 86), entre as "tradições das lembranças e o presente", numa abordagem próxima à de Fernández Sebastián (2014). ${ }^{10}$ Com base em Mastrogregori, pode-se depreender que o presente (seja o contexto de recepção ou o metacrítico) abre condições de "cognoscibilidade dentro da qual é possível perceber o único [exageradamente falando] passado possível" (Mastrogregori 2006, 75, grifos no original). ${ }^{11}$

O que Mastrogregori deseja expressar é que nossa capacidade cognitiva não é meramente autossuficiente, autopoiética ou autocentrada. Nossa cognição dialoga, destarte, com as condições políticas, econômicas, éticas, estéticas, religiosas, jurídicas etc. (Cf. Mastrogregori 2006, 75). Por isso, as condições sociais (contexto de recepção do pesquisador) devem ser vistas como um constructo que é socialmente influenciador (mas não determinante) de nossas percepções e racionalidade. Portanto, há, sinteticamente colocando, uma simbiose entre sujeito/grupo e sociedade.

Além do "contexto de recepción" (Palti 2012, 350), é preciso frisar a proficuidade das referências teóricas discutidas acima para a se problematizar o "el contexto metacrítico" do intelectual, autor ou pesquisador (que corresponde à segunda dimensão apontada acima). Afirma-se isso porque sua inserção num determinado debate oferece possibilidades de diálogo crítico com teorias. Nesse sentido, o autor incorpora as que considera produtivas e rejeita as que são vistas por ele como improdutivas. Instaura-se, aqui, um

\footnotetext{
${ }^{9}$ Neste caso referente ao item terceiro, há uma inspiração no que Armani (2013) chama de rede intelectual. Essa rede é algo que se configura complexamente, mas, em síntese, a inspiração se configura a partir da possibilidade de "apresentar as intenções e motivações concorrentes entre os autores, os modos pelos quais eles configuram uma homogeneidade, bem como suas diferenças, as sociedades nas quais tais autores estão inseridos [...] as culturas às quais eles pertencem, bem como as estruturas argumentativas usadas em comum ao formular suas ideias" (Armani 2013, 142).

10 As diferenças entre os autores é que Fernández Sebastián se preocupa mais em sublinhar os aspectos ligados ao futuro.

$11 \mathrm{O}$ historiador português Fernando Catroga tem uma expressão que define bem a importância do contexto. Trata-se do termo "mediação presentista", que incide tanto na operação de memória, quanto na produção da história como conhecimento (Catroga 2001, 49).
} 
caminho analítico-crítico para o historiador cujo intento é fazer pesquisas sobre a historiografia, visto que se pode estabelecer uma problematização acerca das chaves teóricas mobilizadas por tendências historiográficas.

Para elucidar e exemplificar uma possibilidade de operacionalização da análise do "contexto de recepción", vale trazer à baila um trabalho que, recentemente, emprega tais discussões no campo da historiografia da escravidão. Rafael de B. Marquese (2013) debate com parcela da historiografia da escravidão brasileira - a que foi erigida no período pós-1980. Segundo o historiador agora em apreço, tal historiografia conseguiu ganhos cruciais para pensarmos a vida dos cativos no Brasil escravista, notadamente no período do século XIX.

No entanto, sua crítica é que parte dessa historiografia imergiu (mergulhou) excessivamente na vida cotidiana dos cativos e, com isso, acabou abandonando uma visão holística da escravidão brasileira, ou seja, as articulações que este sistema teceu com o capitalismo histórico global. Sendo assim, a proposta de Marquese (2013) visa recolocar um conceito que foi operacionalizado pela historiografia que tratou da escravidão brasileira nos anos 1960/70, mas, segundo o mencionado historiador, foi abandonado pela historiografia posterior aos anos 1980. Observa-se, nessa proposta de produção de conhecimento postulada por Marquese, um debate que coloca em jogo um diálogo crítico entre teorias e conceitos presentes na história da historiografia, causando impacto na forma como a escravidão será compreendida.

Ainda no que se refere ao contexto metacrítico, é pertinente lembrar e acrescentar que também incidem as possibilidades de articulações temporais entre passado, presente e futuro, haja vista que teorias, conceitos etc. são herdadas(os), remodeladas(os), criticadas(os), rejeitadas(os) etc. $\mathrm{E}$ tais operações envolvem as expectativas de futuro, ou seja, as possibilidades de disputa em torno dos usos ou das construções do passado no presente. ${ }^{12}$

Cumpre assinalar que a terceira dimensão mencionada anteriormente corresponde a um fator não tão problematizado nos estudos atinentes à historiografia, mas que, cada vez mais, tem entrado em cena. Trata-se da subjetividade do pesquisador e sua inserção nas redes de discussão intelectuais.

Ora, ao produzir conhecimento sobre um tema, um pesquisador não somente dialoga com seus contextos de recepção e metacrítico, mas se insere, intelectualmente, em tais contextos. Nesse sentido, é preciso frisar que sua tese a respeito de algum tema ou questão está recheada não só de contexto de recepção ou metacrítico, mas também de sua posição política, ideológica e intelectual, que o insere tanto nos grupos de parceria intelectuais, como nas contendas que forja com outros intelectuais.

Depreende-se, desses debates, que a construção do conhecimento é, portanto, caudatária tanto de valores epistemológicos, como também, em alguma medida, da inserção crítica/política do pesquisador no seu mundo e, por conseguinte, no campo intelectual em que atua e labuta. Nesse sentido, Fernando Catroga, ao abordar o poder mediador que o presente tem na construção do conhecimento histórico, afirma que "[...] a mediação presentista não se esgota na seca análise científica, pois ela implica escolhas que não são social e axiologicamente neutras" (Catroga 2001, 49).

12 O historiador português Fernando Catroga (2001) chama a atenção para o fato de que tanto a história, quanto a memória operam articulando passado, presente e futuro, tendo o contexto como referência matricial. 
A partir desses referenciais, o pesquisador interessado no campo de estudos ligado à historiografia se capacita a alcançar uma visão de que o conhecimento não é construído de forma meramente objetivada. Essa perspectiva deve ser relativizada. E essa relativização não desvalida a epistemologia, mas, sim, abre possibilidades amplas e densas de se problematizar a produção historiográfica, a partir de ferramentas e aparatos teóricos da história intelectual. Reconhece-se, por esse caminho, a complexidade inscrita na produção do conhecimento histórico e sua historicidade.

\section{CONSIDERAÇÕES FINAIS}

O aporte de referências teóricas e metodológicas da história intelectual pode potencializar o trabalho analítico da historiografia. Foi essa a proposta feita e a argumentação que se desenvolveu ao longo deste trabalho. Objetivouse, com isso, posicionar elementos importantes que podem ser balizadores para o trabalho do historiador cujo tema de pesquisa centra-se na historiografia.

Em virtude do que foi registrado, cumpre argumentar que o estudo da historiografia tem dimensões posicional (contexto do tempo presente) e histórica (passado, presente e futuro concatenados em permanências e mudanças) que demandam ao pesquisador a consciência delas (as dimensões), ainda que raramente seja viável dar conta dessas "poliédricas relaciones" (Fernández Sebastián 2014, 7).

A partir de Palti (2012), foram inseridas outras variáveis que estão presentes na problematização acerca da produção do conhecimento histórico, no período posterior aos anos 1970. Nessa fase, pouco a pouco, o contexto de recepção do próprio pesquisador foi problematizado e, no passo seguinte, seu contexto metacrítico também se tornou alvo de possibilidades frutíferas.

Como desdobramento dessas chaves analíticas, conceituais e teóricas, este artigo - que ora deixa suas derradeiras palavras - intentou chamar a atenção para o fato de que a produção do conhecimento histórico, da qual a historiografia é o corolário, deve ser vista sob perspectivas mais amplas e densas. É por esse caminho que o desenvolvimento de conhecimentos ligados à historiografia possa nos levar a pensar não somente a historicidade dos personagens históricos estudados (o passado histórico), mas também as condições históricas do próprio historiador e da realização da pesquisa histórica.

Se atentarmos meticulosa, racional e sensivelmente para essas condições históricas mencionadas, abrem-se, em decorrência, novas possibilidades de agregarmos valores que pesam no processo de produção do conhecimento. Por isso, propõe-se que levar em conta a historicidade da produção historiográfica - incluindo também, neste caso, o lugar intelectual do pesquisador e seus embates intersubjetivos - é estar comprometido com uma produção do conhecimento que está ciente de que a pesquisa não se erige somente em bases epistemológicas, mas também é afetada pela forma como o historiador se insere em seu campo de estudos. 
Nesse sentido, a história intelectual trouxe, de forma potencializada para os estudos historiográficos, possibilidades de explorar a força da subjetividade dentro de um campo de produção de conhecimento com um grau de objetividade. Em outros termos, torna-se mais aguçada, em nossa produção de conhecimento sobre a historiografia, uma chave analítica que nos oferece a possibilidade de desertar para o fato de que as contendas intelectuais (teóricas, políticas e ideológicas) incidem na produção do conhecimento e colaboram para conformar um produto final, ou seja, uma visão perspectivada - mas com um grau de objetividade - sobre o passado.

\section{REFERÊNCIAS}

ADOLFO, Roberto Manoel Andreoni. “As transformações na historiografia da escravidão entre os anos de 1970 e 1980: uma reflexão teórica sobre possibilidades de abordagem do tema". In: Revista de Teoria da História, Ano 6, Número 11, Maio/2014 Universidade Federal de Goiás. ISSN: 2175-5892.

AMBROSINO, Diego Rafael. “As “viradas” lingüística, histórica e interpretativa: novos paradigmas teóricos em História das Idéias e a relação estrutura / agência”. In: $34^{\circ}$ Encontro Anual da Anpocs, setembro de 2010 (ST 34 - Teoria Política: instituição e ação política. Sessão 2 - Ação e Pensamento Políticos: entre o telos aristotélico e a teoria política sem telos).

ARMANI, Carlos Henrique. "História intelectual e redes contextuais". In: Anos 90, Porto Alegre, v. 20, n. 37, p. 137-150, jul. 2013.

AVELAR, Alexandre de Sá; GONÇALVES, Márcia de Almeida. "Giro linguístico e escrita da história nos séculos XX e XXI - Elementos para um debate”. In:

MEDEIROS, Bruno Franco; DE SOUZA, Francisco Gouvea; BELCHIOR, Luna Halabi; RANGEL, Marcelo de Melo; PEREIRA, Mateus H. F. Teoria e Historiografia: Debates Contemporâneos. Jundiaí: Paco Editorial, 2015.

BURKE, Peter. A escola dos Annales (1929-1989): A revolução francesa da historiografia. São Paulo: Unesp, 1997.

CALDAS, Pedro Spinola Pereira. "A nova história cultural (i)". In: TEIXEIRA, Felipe Charbel; CALDAS, Pedro Spinola Pereira. Historiografia contemporânea. v. 1. Rio de Janeiro: Fundação CECIERJ, 2012b, pp. 231-260.

CARDOSO, Ciro Flamarion. "História e paradigmas rivais". In: CARDOSO, Ciro Flamarion \& VAINFAS, Ronaldo (Orgs.). Domínios da História. Rio de Janeiro: Editora Campus (Elsevier), 1997. pp. 1-23.

CATROGA, Fernando. CATROGA, Fernando. Memória, bistória e historiografia. Vol. 1. Universidade de Wisconsin - Madison: Quarteto, 2001.

CHAUBET, Francois. "Enjeu - Histoire des intellectuels, histoire intellectuelle - Bilan provisoire et perspectives". In: Vingtième Siècle. Revue d'bistoire 2009/1 (n 101), p. 179-190.

ELIAS, Norbert. Sobre o tempo. Rio de Janeiro: Jorge Zahar Editor, 1998.

ESCOSTEGUY FILHO, J. C. "Reflexões sobre agência e estrutura na historiografia da escravidão”. Revista Tessituras, v. 6, p. 102-117, 2015.

FALCON, Francisco. "História das idéias". In: CARDOSO, Ciro Flamarion \& VAINFAS, Ronaldo (Orgs.). Dominios da História. Rio de Janeiro: Editora Campus (Elsevier), 1997. pp. 61-90.

FERNÁNDEZ SEBASTIÁN, Javier. "Tradiciones electivas. Cambio, continuidade y ruptura en historia intelectual”. In: Almanack. Guarulhos, n.07, p.5-26, $1^{\circ}$ semestre de 2014. 
FRANZINI, Fábio. "Inovação, tradição, historiografia: um breve diálogo com Javier Fernández Sebastián”. In: Almanack. Guarulhos, n.07, p.33-37, 1º semestre de 2014.

GOMES, Tiago de Melo. "A Força da Tradição a persistência do Antigo Regime historiográfico na obra de Marc Bloch”. In: Varia Historia, Belo Horizonte, vol. 22, n ${ }^{\circ}$ 36: p.443-459, Jul/Dez 2006.

HOBSBAWM, Eric. Introdução: a invenção das tradições. In: HOBSBAWM, Eric; RANGER, Terence (orgs.). A Invenção das Tradições. São Paulo: Paz e Terra, 2006. pp. $9-23$.

JASMIN, Marcelo Gantus. "História dos conceitos e teoria política e social: referências preliminares”. In: RBCS. v. 20, n. 57, fev. 2005, pp. 27-38.

KOSELLECK, Reinhart. Futuro passado: contribuição à semântica dos tempos históricos. Tradução do original alemão: Wilma Patrícia Maas, Carlos Almeida Pereira. Rio de Janeiro: Contraponto, Ed. PUC-Rio, 2006.

KOSELLECK, Reinhart. Los estratos del tiempo: estúdios sobre la historia. Barcelona: Ediciones Paidés, 2001.

LOZANO, Jorge. "La historia como narración”. In: El discurso historico. Madrid: Alianza Editorial, 1987, pp. 113-171.

MALERBA, Jurandir. "EM BUSCA DE UM CONCEITO DE HISTORIOGRAFIA Elementos para uma discussão". In: VARIA HISTÓRLA, Belo Horizonte (MG), $\mathrm{n}^{\circ}$ 27, julho de 2002, pp. 27-47.

MALERBA, Jurandir. "Teoria e história da historiografia”. In: MALERBA, Jurandir (Org.). A história escrita: teoria e história da historiografia. São Paulo: Contexto, 2006. pp. 11-26.

MARQUESE, Rafael de Bivar. "As desventuras de um conceito: capitalismo histórico e a historiografia sobre a escravidão brasileira”. In: Revista de História, São Paulo, n. 169, pp. 223-253, jul/dez. 2013.

MASTROGREGORI, Massimo. "Historiografia e tradição das lembranças". In: MALERBA, Jurandir (Org.). A história escrita: teoria e história da historiografia. São Paulo: Contexto, 2006.

MAUAD, Ana Maria. CAVALCANTE, Paulo. História e Documento. (v. 1) Rio de Janeiro: Fundação CECIERJ, 2013.

NICOLAZZI, Fernando. "História da historiografia e temporalidades: notas sobre tradição e inovação na história intelectual". In: Almanack. Guarulhos, n.07, p.27-32, $1^{\mathrm{o}}$ semestre de 2014.

NOIRIEL, Gerard. "La crise des paradigmes". In: Sur la "crise" de l'bistoire. Paris: Éditions: Belin, 1996, pp. 123-171.

PALERMO, Luis Claudio. "A aceleração do tempo e processo histórico em Reinhart Koselleck e Timothy Brook". In: Transversos: Revista de História. Rio de Janeiro, n. 09, abr. 2017b, pp. 300-325.

PALERMO, Luis Claudio. "Tempo e temporalidades: transformações semânticas modernas e alguns desdobramentos na produção do conhecimento histórico". In: Temporalidades - Revista de História, ISSN 1984-6150, Edição 23, V. 9, N. 1 (jan./abril 2017a).

PALTI, Elías J. “'Giro linguístico’ e historia intelectual”. In: Giro linguístico e bistoria intelectual. Bernal: Universidad Nacional de Quilmes, 2012.

PALTI, Elías J. "La nueva historia intelectual y sus repercusiones em América Latina”. In: História Unisinos, 11(3):297-305, Setembro/Dezembro 2007.

RANGEL, Marcelo de Mello; ARAÚJO, Valdei Lopes de. "Apresentação - Teoria e história da historiografia: do giro linguístico ao giro ético-político". In: hist. historiogr., Ouro Preto, n. 17, abril, 2015, p. 318-332.

RODRIGUES, Henrique Estrada. "Lévi-Strauss, Braudel e o tempo dos historiadores". In: Revista Brasileira de História. São Paulo, v. 29, n. 57, 2009, pp. 165-186. 
SILVA, Ricardo. "História intelectual e teoria política". In: Rev. Sociol. Polit., Curitiba, v. 17, n. 34, p. 301-318, out. 2009.

TOMICH, Dale. "A Ordem do Tempo Histórico: a Longue Durée e a Micro-História". In: Almanack. Guarulhos, n.02, p.38-51, 20 semestre de 2011.

VAINFAS, Ronaldo. “Colonização, Miscigenação e questão racial: notas sobre equívocos e tabus da historiografia brasileira”. In: Revista Tempo, Niterói, v. 8, p. 7-22, 1999.

VAINFAS, Ronaldo. "História das mentalidades e história cultural". In: CARDOSO, Ciro Flamarion \& VAINFAS, Ronaldo (Orgs.). Domínios da História. Rio de Janeiro: Editora Campus (Elsevier), 1997. pp. 127-162.

WEHLING, Arno. "Historiografia e epistemologia histórica". In: MALERBA, Jurandir (Org.). A história escrita: teoria e história da historiografia. São Paulo: Contexto, 2006.

Um diálogo produtivo entre a nova história intelectual e os estudos historiográficos

Artigo recebido em 02/11/2020 • Aceito em 08/06/2021.

DOI | doi.org/10.5216/rth.v24i1.55714

Revista de Teoria da História | issn 2175-5892

\section{@}

Este é um artigo de acesso livre distribuído nos termos da licença Creative Commons Attribution, que permite uso irrestrito, distribuição e reprodução em qualquer meio, desde que o trabalho original seja citado de modo apropriado 